\title{
Tumour cells down-regulate CCN2 gene expression in co-cultured fibroblasts in a Smad7- and ERK-dependent manner
}

Beverley A van Rooyen ${ }^{1,2,3+}$, Georgia Schäfer ${ }^{1,2+}$, Virna D Leaner ${ }^{2}$ and M lqbal Parker ${ }^{1,2^{*}}$

\begin{abstract}
Background: Recent studies have revealed that interactions between tumour cells and the surrounding stroma play an important role in facilitating tumour growth and invasion. Stromal fibroblasts produce most of the extracellular matrix components found in the stroma. The aim of this study was to investigate mechanisms involved in tumour cell-mediated regulation of extracellular matrix and adhesion molecules in co-cultured fibroblasts. To this end, microarray analysis was performed on CCD-1068SK human fibroblast cells after direct co-culture with MDA-MB231 human breast tumour cells.

Results: We found that the expression of both connective tissue growth factor (CTGF/CCN2) and type I collagen was negatively regulated in CCD-1068SK fibroblast cells under direct co-culture conditions. Further analysis revealed that Smad7, a known negative regulator of the Smad signalling pathway involved in CCN2 promoter regulation, was increased in directly co-cultured fibroblasts. Inhibition of Smad7 expression in CCD-1068SK fibroblasts resulted in increased CCN2 expression, while Smad7 overexpression had the opposite effect. Silencing CCN2 gene expression in fibroblasts led, in turn, to a decrease in type I collagen mRNA and protein levels. ERK signalling was also shown to be impaired in CCD-1068SK fibroblasts after direct Co-culture with MDA-MB-231 tumour cells, with Smad7 overexpression in fibroblasts leading to a similar decrease in ERK activity. These effects were not, however, seen in fibroblasts that were indirectly co-cultured with tumour cells.
\end{abstract}

Conclusion: We therefore conclude that breast cancer cells require close contact with fibroblasts in order to upregulate Smad7 which, in turn, leads to decreased ERK signalling resulting in diminished expression of the stromal proteins CCN2 and type I collagen.

Keywords: Feedback regulation, CCN2, Type 1 collagen, Signal transduction, Host-tumour cell interaction, Breast cancer

\section{Background}

In normal mammary tissue, epithelial cells form ducts and glands that are separated from the surrounding connective tissue by a basement membrane. The connective tissue, or stroma, is made up of fibrillar extracellular matrix (ECM), capillaries and cells such as fibroblasts, immune and inflammatory cells $[1,2]$ and serves as a barrier that impedes tumour development [3-5].

\footnotetext{
* Correspondence: iqbal.parker@icgeb.org

${ }^{\dagger}$ Equal contributors

'International Centre for Genetic Engineering and Biotechnology (ICGEB), Anzio Rd Observatory, Cape Town 7925, South Africa

${ }^{2}$ Division of Medical Biochemistry \& the Institute of Infectious Diseases and Molecular Medicine, Faculty of Health Sciences, University of Cape Town, Cape Town, South Africa

Full list of author information is available at the end of the article
}

However, complex tumour-stromal interactions may result in changes to the stroma that facilitate breakdown of the basement membrane and allows tumour cells to invade the surrounding ECM. Here, the tumour cells interact with both ECM components and stromal cells in a way that would not occur under normal conditions, and this may facilitate further tumour invasion and metastasis [3,5-10]. Stromal fibroblasts are responsible for synthesizing and depositing most of the ECM components and, therefore, interactions between tumour cells and fibroblasts play an important role in determining how tumour cells alter the ECM to facilitate tumour invasion.

Structural proteins such as collagen, fibronectin and laminin make up a large proportion of the ECM. However, another group of proteins known as matricellular proteins are

\section{() BioMed Central}

(c) 2013 van Rooyen et al.; licensee BioMed Central Ltd. This is an Open Access article distributed under the terms of the Creative Commons Attribution License (http://creativecommons.org/licenses/by/2.0), which permits unrestricted use, distribution, and reproduction in any medium, provided the original work is properly cited. 
also found associated with the ECM. Matricellular proteins do not play a direct role in maintaining physical structure but are rather involved in modulating and co-mediating cellular responses through interactions with cell surface receptors, growth factors, cytokines and matrix proteins $[11,12]$. Connective tissue growth factor (CTGF) or CCN2 is a member of the CCN family of matricellular proteins and mainly acts through interactions with cell adhesion receptors such as integrins and heparin sulfate proteoglycans (HSPGs) [12]. CCN2 expression is regulated mainly at the transcriptional level $[13,14]$ and one of the most potent inducers of $\mathrm{CCN} 2$ gene expression in fibroblasts, but not in epithelial cells, is transforming growth factor beta (TGF $\beta$ ) $[14,15]$. Regulation of CCN2 gene expression by TGF $\beta$ involves the association of a $\operatorname{Smad} 3 / \mathrm{Smad} 4$ complex with a Smad binding element (SBE) on the CCN2 promoter [16]. The CCN2 promoter also has a TGF $\beta$ response element (TGF $\beta R E$ ) which appears to be important for the regulation of basal CCN2 gene expression in fibroblasts, and is therefore also called the basal control element (BCE-1) [16]. Other signalling pathways that are involved in basal and TGF $\beta$-mediated CCN2 up-regulation include the Ras/ MEK/ERK and protein kinase C (PKC) pathways [14,17].

$\mathrm{CCN} 2$ is thought to act mainly as a co-mediator of TGF- $\beta$ 's ability to promote type I collagen synthesis, as ccn2-/- embryonic fibroblasts were unable to induce type I collagen synthesis in response to TGF $\beta$ [18]. An important relationship therefore exists between TGF $\beta$, CCN2 and type I collagen, and in aged human skin ( $\geq 80$ years) the expression of all three of these proteins is co-ordinately reduced when compared to levels in younger skin samples (21-30 years) [19].

Current knowledge of the role tumour cells play in regulating the expression of various components of the ECM in the tumour environment is limited. In this study we investigated this further by using microarray technology to measure changes in the expression of ECM components and adhesion molecules in human fibroblasts that were cocultured with human breast tumour cells. We show that MDA-MB-231 breast tumour cells negatively regulate CCN2 and type I collagen gene expression in CCD1068SK fibroblasts in a Smad7-dependent manner through decreased activation of the MEK/ERK signalling pathway. This effect was only observed in CCD-1068SK fibroblasts that were directly co-cultured with MDA-MB-231 tumour cells, suggesting that breast tumour cells require close contact with fibroblasts in the tumour microenvironment to influence the expression of ECM components.

\section{Results}

The effect of tumour cell/fibroblast co-culture on ECM and adhesion molecule gene expression

To investigate the effect of close contact with tumour cells on the expression of cell adhesion and ECM components in fibroblasts, cells were directly cocultured and subsequently separated before further gene expression analysis. CCD-1068SK human fibroblasts pre-labelled with $\mathrm{PKH}-67$ green fluorescent dye were mixed with an equal number of MDA-MB-231 human breast tumour cells, co-cultured for 48 hours and separated from the tumour cells by FACS for subsequent RNA isolation to profile the expression of several ECM genes by means of the Oligo GEArray ${ }^{\circ}$ Human Extracellular Matrix and Adhesion Molecules microarray (SABiosciences) (Additional file 1: Table S1). The array analysis showed that direct co-culture with MDA-MB231 tumour cells led to an increase in the expression of matrix metalloprotease 1 (MMP1) in CCD-1068SK fibroblasts relative to CCD-1068SK mono-cultures while the expression of a number of collagen genes was down-regulated (Table 1). Interestingly, the expression of connective tissue growth factor (CTGF/CCN2) was substantially decreased in co-cultured fibroblasts.

The microarray findings for MMP1, COL1A1, COL1A2 and CCN2 were independently confirmed by quantitative real-time RT-PCR, showing that MMP1 gene expression was significantly up-regulated while COL1A1, COL1A2 and CCN2 mRNA levels were significantly decreased in fibroblasts that were co-cultured with tumour cells (Figure 1A). Both CCN2 and type I collagen are known to be positively regulated in response to TGF $\beta$ via the Smad signalling pathway $[14,20]$ and, since both CCN2 and type I collagen were negatively regulated in fibroblasts in response to tumour cell co-culture, we investigated the expression of the negative regulator of TGF $\beta$ signalling, Smad7. Indeed, Smad7 gene expression was significantly increased in co-cultured compared to mono-cultured fibroblasts (Figure 1A). These findings were further supported by Western Blot analysis showing that Smad7 protein was elevated in cocultured fibroblasts while both $\mathrm{CCN} 2$ and type I

$\begin{aligned} & \text { Table } 1 \text { Differential expression of genes in CCD-1068SK } \\
& \text { fibroblasts after co-culture with MDA-MB-231 breast } \\
& \text { tumour cells }\end{aligned}$
\begin{tabular}{lc} 
Gene name & $\begin{array}{r}\text { Relative expression in co-cultures } \\
\text { vs. mono-cultures [CCD(MDA)/CCD(CCD)] }\end{array}$ \\
\hline MMP1 & 1.26 \\
COL1A1 & 0.50 \\
COL18A1 & 0.40 \\
COL6A3 & 0.36 \\
COL12A1 & 0.29 \\
COL4A2 & 0.18 \\
COL8A1 & 0.14 \\
COL5A3 & 0.05 \\
CCN2 & 0.0001 \\
\hline
\end{tabular}




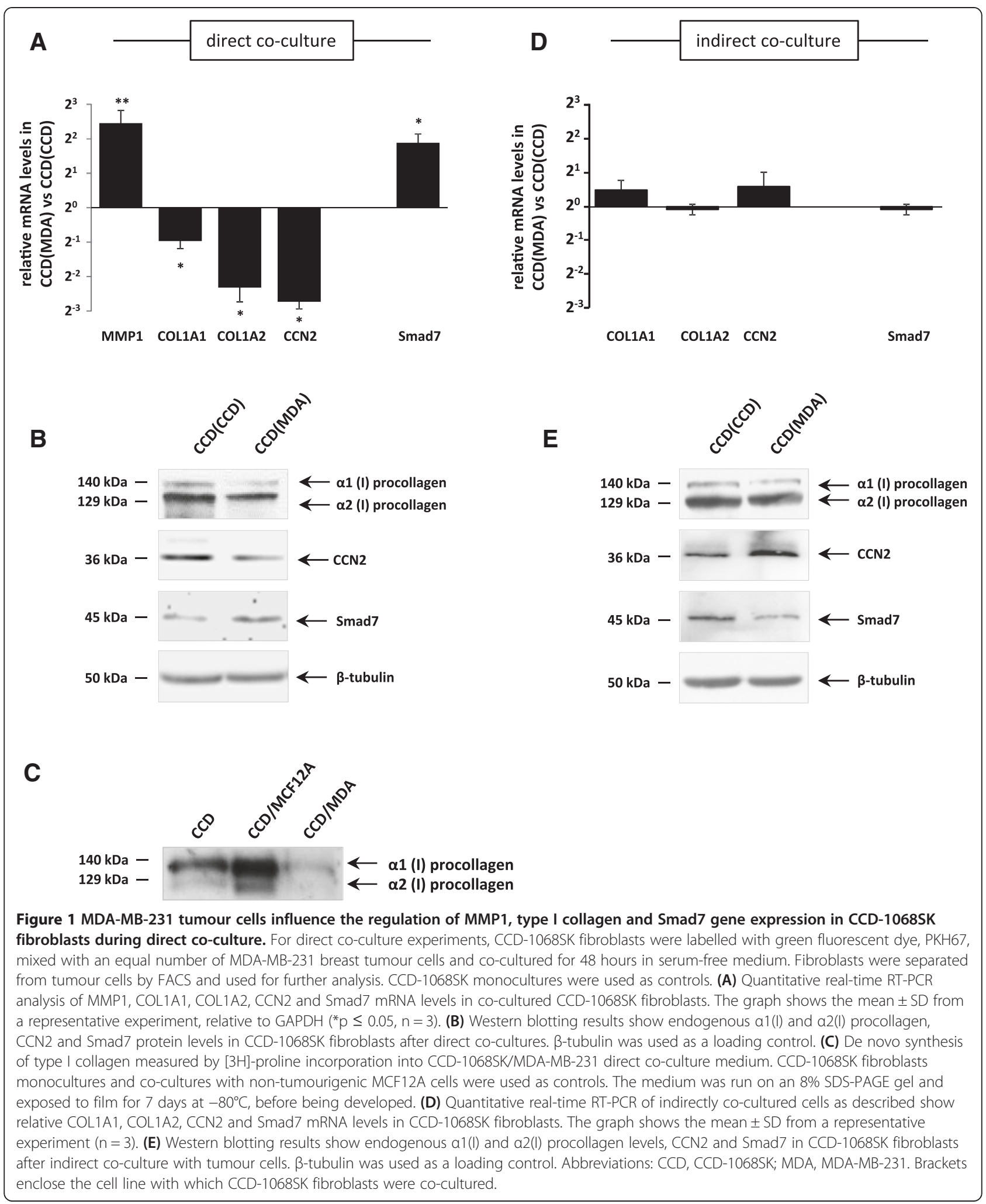

collagen levels were decreased (Figure 1B). The secretion of radioactively labeled $\alpha 1$ (I) and $\alpha 2$ (I) procollagen chains synthesized by CCD-1068SK fibroblasts during co-culture with MDA-MB-231 cells was investigated by adding $\left[{ }^{3} \mathrm{H}\right]$-proline to the culture medium during the period of co-culture. We found lower levels of 
exogenous $\alpha 1(\mathrm{I})$ and $\alpha 2(\mathrm{I})$ procollagen in the medium from CCD-1068SK/MDA-MB-231 co-cultures compared to levels in CCD-1068SK monocultures or CCD-1068SK co-cultured with MCF12A breast epithelial cells that served as a benign control (Figure 1C). These results suggest that, when in direct contact with fibroblasts, MDA-MB-231 tumour cells were able to negatively regulate the expression of certain ECM components in CCD1068SK fibroblasts, including CCN2 and type I collagen. This regulation may occur through up-regulation of the negative regulator, Smad7.

Tumour cells may be communicating with fibroblasts in a paracrine manner by secreting soluble factors such as cytokines and growth factors that can modulate Smad7, CCN2 and type I collagen gene expression in neighbouring fibroblasts via such secreted factors. To investigate this possibility, an indirect co-culture system was used in which CCD-1068SK fibroblasts were separated from the MDA-MB-231 tumour cells using a transwell insert with a $0.2 \mu \mathrm{m}$ pore size. This allowed secreted factors to pass through but prevented direct contact between fibroblasts and tumour cells. Analysis of gene expression by quantitative real-time RT-PCR in indirectly co-cultured CCD-1068SK fibroblasts revealed that tumour cells did not influence the expression of COL1A1, COL1A2, CCN2 or Smad7 when compared to fibroblast monocultures (Figure 1D). In fact, Western Blot analysis revealed that $\mathrm{CCN} 2$ protein levels were increased while Smad7 was decreased (Figure 1E). These results suggest that tumour cell-mediated regulation of Smad7, CCN2 and type I collagen expression in fibroblasts was dependent on the contacts with or close proximity of the tumour cells to these fibroblasts.

\section{Smad7 influences the expression of CCN2 and type I collagen gene expression}

To determine whether the observed increase in Smad7 was associated with decreased CCN2 and type I collagen levels, Smad7 gene expression in CCD-1068SK fibroblasts was altered by both gene silencing as well as transient overexpression. siRNA mediated knock-down of Smad7 in fibroblasts resulted in a substantial increase in both CCN2 mRNA and protein levels compared to controls (Figure 2A and B). Although all Western Blots were performed under denaturing conditions, we observed the appearance of both monomeric and dimeric forms of CCN2 protein at $36 \mathrm{kDa}$ and $72 \mathrm{kDa}$, respectively, with a specific increase in CCN2 dimerization in Smad7 knock-down fibroblasts (Figure 2B). The levels of $\alpha 1(\mathrm{I})$ and $\alpha 2(\mathrm{I})$ procollagen were also increased in Smad7 knock-down fibroblasts compared to control fibroblasts, although only COL1A1 levels appeared to be affected at an mRNA level (Figure 2A and B).

Transfecting CCD-1068SK fibroblasts with the Smad7 overexpression plasmid pORF9-hSmad7 caused a significant decrease in CCN2, COL1A1 and COL1A2 mRNA levels (Figure $2 \mathrm{C}$ ), which is in agreement with the expression data shown in Figure 1A. While Smad7 protein levels were found to peak 8 hours post transfection, the effect on CCN2 and type I collagen gene expression was only observed after 48 hours (Figure 2D). These results suggest that increased levels of Smad7 in CCD-1068SK fibroblasts can negatively affect the expression of both CCN2 and type I collagen, as observed in fibroblasts after direct co-culture with MDA-MB-231 tumour cells (Figure $1 \mathrm{~A}$ and $\mathrm{B}$ ).

\section{CCN2 is a positive regulator of type I collagen gene expression}

Previous studies have suggested that changes in CCN2 expression can affect type I collagen gene expression in fibroblasts $[19,21]$. We therefore investigated whether CCN2 knock-down in CCD-1068SK fibroblasts would have a downstream effect on type I collagen gene expression. CCD-1068SK fibroblasts were transfected with increasing concentrations of CCN2 siRNA and incubated for an additional 48 hours. Western blot analysis of the extracted protein showed that silencing CCN2 had a negative regulatory effect on both $\alpha 1(\mathrm{I})$ and $\alpha 2(\mathrm{I})$ procollagen gene expression (Figure 3A). CCD-1068SK fibroblasts transfected with $40 \mathrm{nM}$ CCN2 siRNA were also subjected to quantitative real-time RT-PCR analysis, and showed an associated decrease in both COL1A1 and COL1A2 mRNA levels observed as a result of CCN2 knock-down (Figure 3B). Inhibition of CCN2 gene expression in CCD-1068SK fibroblasts therefore associates with decreased type I collagen expression in these cells.

\section{A role for ERK1/2 in the regulation of CCN2 and type I collagen gene expression}

Previous studies have shown that the MEK/ERK signalling pathway is a positive regulator of $\mathrm{CCN} 2$ gene expression $[14,17,22]$. We therefore investigated whether changes in MEK/ERK signalling could account for the observed decreased $\mathrm{CCN} 2$ gene expression in CCD1068SK fibroblasts co-cultured with MDA-MB-231 tumour cells. We found that direct, but not indirect, coculture of fibroblasts with tumour cells led to a substantial decrease in phosphorylated ERK 1 and ERK 2 when compared to fibroblast monocultures (Figure 4A) while the levels of total ERK remained unchanged in both direct and indirect co-cultures. Since fibroblasts directly co-cultured with tumour cells were found to have elevated $\mathrm{Smad} 7$ gene expression with downstream effects on CCN2 and type I collagen (Figures 1 and 2), we therefore asked whether Smad7 affects activation of the ERK signalling pathway. We transiently transfected CCD-1068SK fibroblasts with pORF-hSmad7 and found that overexpression of Smad7 (as shown in Figure 2C) 


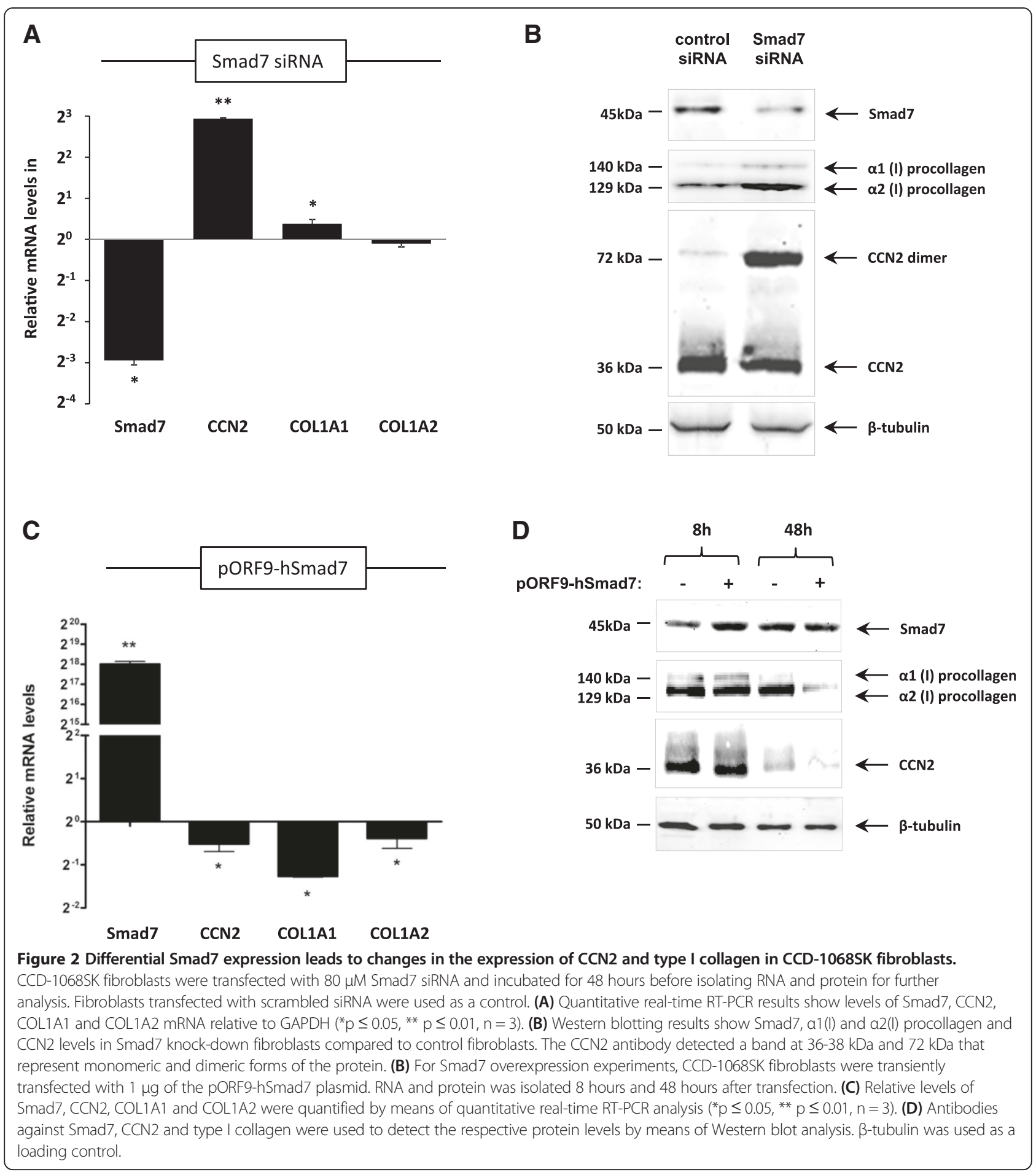

led to a decrease in activated ERK1 and ERK2, with very low levels of phosphorylated ERK1/2 observed 48 hours post transfection (Figure 4B).

To determine whether decreased activation of the MEK/ERK signalling pathway could be associated with decreased expression of CCN2 and type I collagen, CCD-1068SK fibroblasts were cultured in the presence of the MEK pathway inhibitor U0126. Western blot results showed that decreased ERK $1 / 2$ phosphorylation resulted in a decrease in $\mathrm{CCN} 2$ protein and mRNA levels in CCD-1068SK fibroblasts (Figure 3C and D) while no significant effect was observed on COL1A1 and COL1A2 gene expression. These results suggest that the increase in Smad7 levels observed in directly co-cultured 

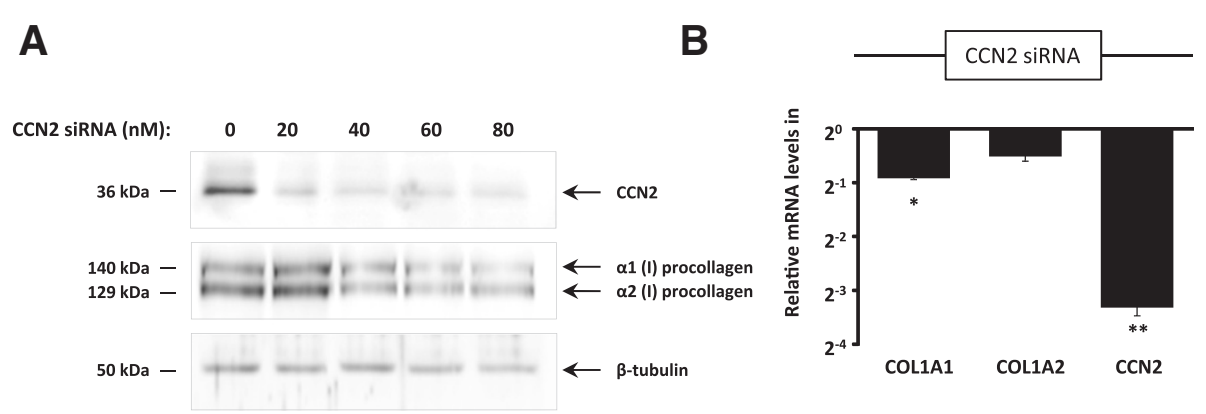

Figure 3 CCN2 knock-down leads to decreased expression of type I collagen. CCD-1068SK fibroblasts were transfected with 20 to $80 \mu \mathrm{M}$ of CCN2 siRNA and incubated for 48 hours before isolating RNA and protein for further analysis. Fibroblasts transfected with scrambled siRNA were used as a control. (A) CCN2 and type I procollagen protein levels in CCN2 knock-down fibroblasts, analysed by Western blotting. $\beta$-tubulin was used as a loading control. (B) Real-time PCR results show relative COL1A1, COL1A2 and CCN2 mRNA levels, relative to GAPDH $\left({ }^{*} \mathrm{P} \leq 0.05\right.$, ** $\mathrm{p} \leq 0.01, \mathrm{n}=3)$.

fibroblasts can negatively regulate MEK/ERK signalling which has downstream effects mainly on $\mathrm{CCN} 2$ expression.

\section{Discussion}

It has recently been shown that genetic mutations are not the only factors that play a role in the progression of transformed epithelial cells to invasive tumour cells, but that continuous communication with the surrounding stroma may also facilitate tumour development $[8,23,24]$. If tumours progress to the invasive stage, the basement membrane which usually separates the tumour cells from the fibroblasts is degraded, allowing tumour cells to invade into the surrounding stroma where they come into close contact with stromal fibroblasts. Since these fibroblasts are the main producers of the components making up the ECM, close interactions with tumour cells could influence ECM production by these fibroblasts with further consequences for tumour migration and invasion.

In the present study we established an in vitro coculture model of MDA-MB-231 breast tumour cells and normal CCD-1068SK breast skin fibroblasts and applied microarray analysis to identify the genes affected by direct cell-cell contact during culture. We showed that tumour cells are able to down-regulate the expression of ECM genes such as type I collagen and CCN2, while upregulating the expression of collagenases such as MMP1 in neighbouring fibroblasts. Moreover, we identified Smad7 as a putative negative regulator of both CCN2 and type I collagen gene expression in fibroblasts, with Smad7 mRNA and protein levels being significantly increased in CCD-1068SK fibroblasts that were directly co-cultured with MDA-MB-231 tumour cells. Importantly, these effects were found to be a result of direct cell-cell contact and not mediated by growth factors or cytokines secreted into the medium, as shown by indirect co-culture experiments.
Previous studies have shown that overexpression of Smad7 reduces TGF $\beta$-stimulated CCN2 gene expression, but has no effect on the basal expression of CCN2 [16]. However, ELISA analysis performed in our laboratory showed that CCD-1068SK fibroblasts secrete TGF $\beta$ in monocultures (results not shown), and it is therefore possible that Smad7 plays a role in negatively regulating autocrine TGF $\beta$ in these fibroblasts. Moreover, CCN2 has been shown to act as a co-mediator of TGF $\beta$ 's ability to promote type I collagen synthesis $[18,25]$, suggesting that the decreased type I collagen gene expression observed in CCD-1068SK fibroblasts co-cultured with MDA-MB-231 tumour cells could occur as a result of the negative regulatory effect of increased Smad7 expression on CCN2 gene expression. Indeed, the siRNA experiments in CCD-1068SK fibroblasts showed that knockdown of CCN2 led to decreased levels of type I collagen, also confirming previous studies showing that changes in CCN2 expression can affect type I collagen gene expression in fibroblasts $[19,21]$. Smad7 overexpression has previously been shown to decrease COL1A1 mRNA levels in normal human fibroblasts [26], which supports our results obtained in fibroblasts directly co-cultured with tumour cells.

Transcription of Smad7 is known to be positively regulated by TGF $\beta$ signalling, leading to downstream inhibition of TGF $\beta /$ Smad signalling by Smad7 as part of a negative feedback loop [27-29]. Overexpression of Smad7 in tumour-associated fibroblasts may therefore result in their unresponsiveness to TGF $\beta$ signalling. Indeed, recent evidence suggests that fibroblasts unable to respond to TGF $\beta$ facilitate tumour growth [30]. By transplanting fibroblasts lacking the TGF $\beta$ receptor into mice together with mammary carcinoma cells, the aggressiveness and metastatic ability of the resulting tumours was shown to increase when compared to that observed in tumour cells transplanted together with normal fibroblasts. The altered fibroblasts produced TGF $\alpha$ 
A
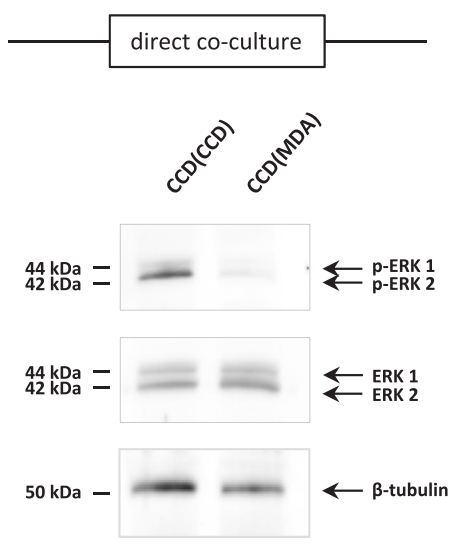

B

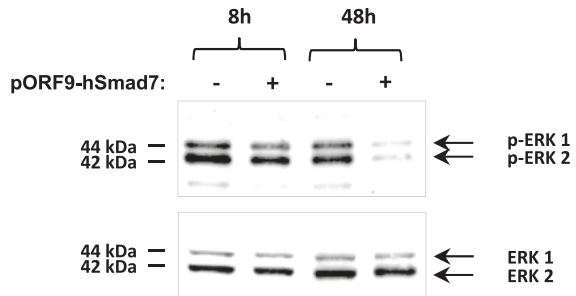

C

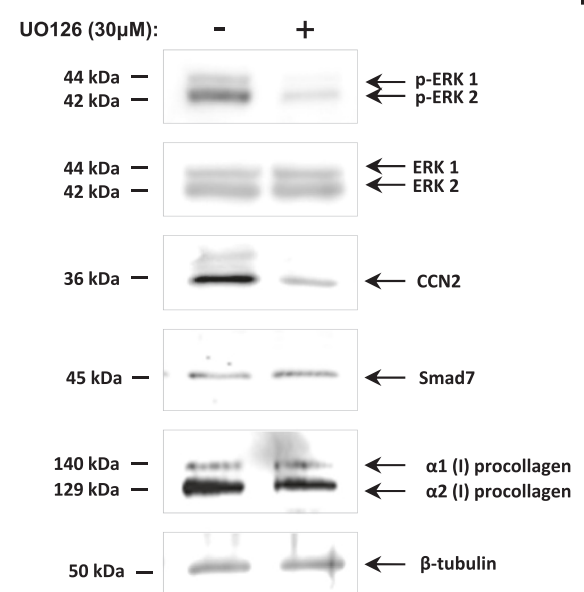

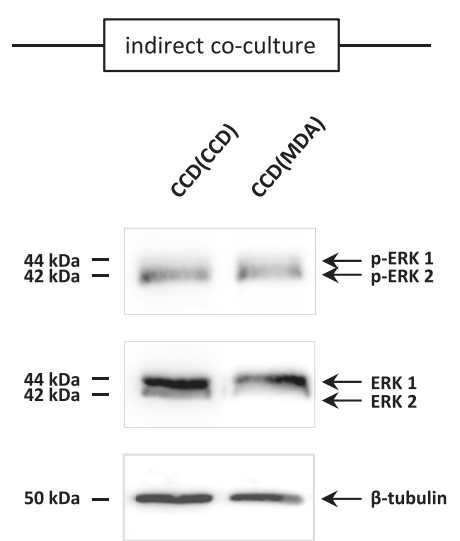

D

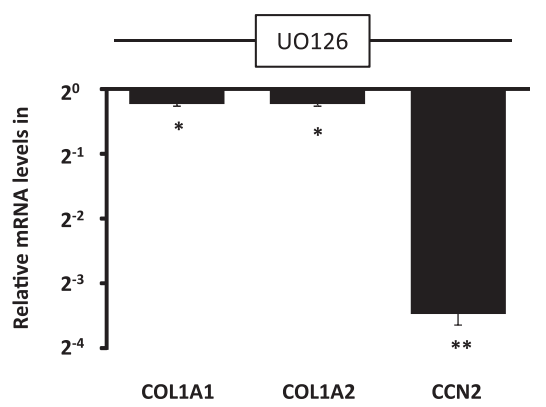

Figure 4 Smad7-dependent decreased activation of ERK1/2 in CCD-1068SK fibroblasts directly co-cultured with MDA-MB-231. (A) CCD1068SK fibroblasts were directly or indirectly co-cultured with an equal number of MDA-MB-231 tumour cells and incubated for 48 hours. Levels of p-ERK 1/2 (T402, Y404) were measured in co-cultured CCD-1068SK fibroblasts by means of Western blot analysis and compared to levels in CCD-1068SK monocultures. ERK1/2 and $\beta$-tubulin levels were detected as experimental controls. (B) CCD-1068SK fibroblasts transfected with the pORF9-hSmad7 and overexpressing Smad7, as shown in Figure 2D, were used for further analysis of p-ERK $1 / 2$ levels. ERK1/2 and $\beta$-tubulin served as controls. (C) The MEK/ERK inhibitor U0126 was added to CCD-1068SK fibroblasts and incubated for 48 hours. Protein was isolated for Western blot analysis of p-ERK $1 / 2$ as well as CCN, Smad7 and type I procollagen. ERK1/2 and $\beta$-tubulin were used as controls. (D) Quantitative real-time RT-PCR was used to measure COL1A1, COL1A2 and CCN2 mRNA levels in CCD-1068SK fibroblasts incubated with U0126 inhibitor for 48 hours $\left({ }^{*} p \leq 0.05,{ }^{* *} p \leq 0.01, n=3\right)$.

and hepatocyte growth factor (HGF) which resulted in accelerated tumour cell growth. Since TGF $\beta$ also usually suppresses destructive immune and inflammatory responses [31,32], preventing the action of this tumour suppressor in breast cancer could result in tumourpromoting inflammatory conditions $[23,33]$.

The upstream events leading to Smad7 overexpression in the herein described direct co-culture model of CCD- 
1068SK fibroblasts and MDA-MB-231 tumour cells has not yet been determined. Our results suggest that regulation occurs at the transcriptional level as Smad7 mRNA levels were found to be significantly increased. Previous studies investigating Smad7 regulation have mainly focussed on the effect of various cytokines on Smad7 expression. Those found to increase Smad7 levels include IFN $\gamma$ via JAK/Stat signalling [34] and IL1 $\beta$ via either JNK or NFkB activation [35]. However, since Smad7 overexpression only occurred in fibroblasts directly co-cultured with tumour cells, this suggests that cell surface factors may be involved in regulation of Smad7. Further investigations would need to be performed to determine these factors.

Investigating the intracellular signalling events leading to CCN2 and type I collagen down-regulation, we found that tumour cell-mediated up-regulation of Smad7 negatively affected the MEK/ERK pathway. However, inhibition of this pathway had more dramatic effects on CCN2 expression while type I collagen was only slightly decreased. Previous studies have suggested that Ras/MEK/ERK signalling positively regulates $\mathrm{CCN} 2$ promoter activity and is required for basal CCN2 promoter activity $[14,17,36,37]$. However, the effect of MEK/ERK signalling on type I collagen gene expression is not clear. Some studies suggest that MEK/ERK activation negatively regulates type I collagen expression [38]. However, addition of IL-4 or IL-13 to dermal fibroblasts also increases type I collagen promoter activity in an ERK-dependent manner [39]. The effect of MEK/ERK signalling on type I collagen gene expression therefore appears to be dependent on interactions with other signalling pathways and on the cell context. Recent studies have shown that TGF $\beta$-mediated up-regulation of both $\mathrm{CCN} 2$ and type I collagen in fibroblasts requires activation of Alk1 (TGFBRI)/Smad1 and downstream ERK1/2 signalling [40] and that the association of $\mathrm{CCN} 2$ with $\beta 3$ integrin is required for TGF $\beta$-mediated Smad1 phosphorylation [25]. Silencing Smad1 gene expression resulted in a decrease in the expression of both TGF $\beta$-stimulated CCN2 and type I collagen gene expression as well as basal type I collagen gene expression [40]. CCN2 has, in turn, been shown to activate ERK1/2 signalling by adhesion to the alpha1/beta6 integrin receptor or syndecan 4 , a heparin sulphate proteoglycan $[18,41]$. The MEK/ERK signalling pathway therefore appears to play an important role in positively regulating CCN2 expression which, in turn, leads to further increased activation of MEK/ERK in a positive feedback loop. Deregulation of the MEK/ERK signalling pathway in fibroblasts close to or adjacent to tumour cells could therefore have important implications for ECM synthesis and homeostasis.

Previous studies have shown that levels of type I collagen gene expression were only decreased in later stages of breast tumour progression [42] and in melanoma tissue [43]. The negative regulation of tumour cells on $\mathrm{CCN} 2$ and type I collagen gene expression in fibroblasts may therefore be more likely to occur during the invasive stages of breast cancer, when tumour cells are in close contact with surrounding fibroblasts as a result of basement membrane degradation. Close association with invasive tumour cells could therefore cause the balance of ECM synthesis/degradation to be disturbed by decreasing the production of type I collagen and CCN2 in neighbouring fibroblasts and concurrently causing an increase in the expression of MMP1, a metalloproteinase that degrades type I collagen. Previous studies performed on highly invasive melanomas have shown that destabilization and degradation of the type I collagen matrix allows melanoma cells to evade the growth arrest and apoptosis that these cells would normally undergo in the presence of type I collagen matrix [43]. Inhibiting MMP expression in MDA-MB-231 cells has also been shown to inhibit the migration of these tumour cells through a bone marrow fibroblast monolayer [44]. The results obtained in these studies suggest that the decreased $\mathrm{CCN} 2$ and type I collagen matrix production and increased MMP expression observed in our model system of co-cultured CCD-1068SK fibroblasts could facilitate MDA-MB-231 tumour cell invasion through the ECM. However, further studies including primary human fibroblasts as well as breast tumour samples will need to be undertaken to support the observations described here.

\section{Conclusions}

The co-culture model presented in this study revealed that tumour cells influenced ECM gene expression by direct cell-cell contact with fibroblasts. The observed effects were found to be mediated by increased levels of Smad7 that negatively influenced type I collagen and CCN2 expression, the latter occurring in a MEK/ERK dependent manner (Figure 5). To our knowledge, this is the first study showing a negative regulatory effect of Smad7 on CCN2 and type I collagen expression that is dependent on direct contact between fibroblasts and tumour cells. This type of close contact between tumour cells and fibroblasts is only possible in the later stages of breast cancer progression, when the basement membrane separating these two cell types has been degraded, and the resulting decrease in fibroblast-mediated production of the surrounding extracellular matrix could facilitate further tumour invasion and metastasis. Our results highlight the fact that invasive tumour cells may have effects on closely associated fibroblasts that would not occur under normal conditions and which could allow tumour cells to escape the inhibitory effects of the matrix, facilitating further tumour migration and invasion.

\section{Methods}

\section{Cell culture}

The cell lines CCD-1068SK (human breast fibroblasts), MDA-MB-231 (human breast tumour cells) and MCF12A (human non-tumorigenic epithelial cells) were purchased 


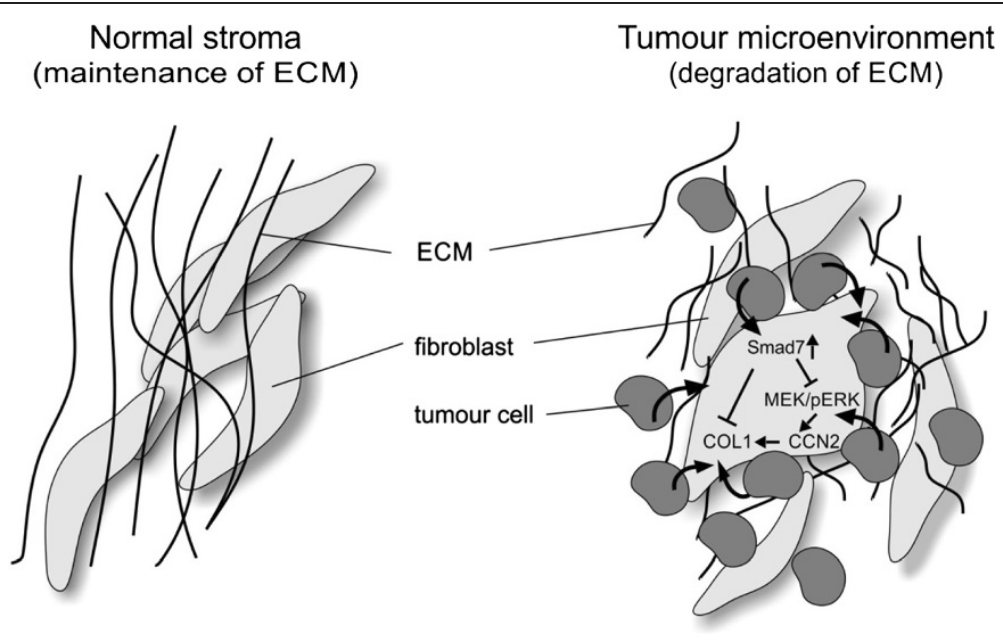

Figure 5 Proposed model of breast tumour-mediated regulation of CCN2 and type I collagen in neighbouring fibroblasts in the tumour microenvironment. While fibroblasts in the normal stroma maintain the structure and function of the ECM, direct contact of tumourassociated fibroblasts with breast tumour cells in the tumour microenvironment leads to degradation of the ECM and/or fibrosis. We hypothesise that this is caused by increased expression of Smad7 that downstream negatively affects the expression of CCN2 and type I collagen, partly through inactivation of the MEK/ERK signalling pathway (illustration by I. Jastram).

from ATCC and were grown in Dulbecco's modified Eagle's medium (DMEM, Invitrogen) supplemented with $10 \%(\mathrm{v} / \mathrm{v})$ heat-inactivated fetal calf serum (FCS, Invitrogen), $100 \mu \mathrm{g} /$ $\mathrm{ml}$ streptomycin and $100 \mathrm{U} / \mathrm{ml}$ penicillin (Invitrogen) in a humidified atmosphere $\left(5 \% \mathrm{CO}_{2}\right)$ at $37^{\circ} \mathrm{C}$.

\section{Direct co-culture}

A total of $5 \times 10^{6} \mathrm{CCD}-1068 \mathrm{SK}$ fibroblasts were labelled with PKH67 green fluorescent dye (Sigma) in diluent C, according to the manufacturer's instructions. After extensive washing, the fibroblasts were mixed with an equal number of MDA-MB-231 tumour cells, and $1.4 \times 10^{6}$ cells were seeded into $150 \mathrm{~cm}$ dishes. In parallel, $1.4 \times 10^{6}$ CCD-1068SK fibroblasts were seeded into separate $150 \mathrm{~cm}$ dishes and served as a control. Cells were allowed to settle in complete medium for at least 12 hours before being washed twice with $1 \times \mathrm{PBS}$ and incubated in serum-free medium for a further 48 hours.

\section{Indirect co-culture}

CCD-1068SK at a density of $2 \times 10^{5}$ cells/well were seeded into 6-well plates while an equal number of MDA-MB-231 or CCD-1068SK cells were seeded on transwell inserts (NUNC, membrane pore size $0.2 \mu \mathrm{m}$ ) in separate 6-well plates. Cells were allowed to settle in complete medium for at least 12 hours before inserts were transferred into the 6well plates containing the fibroblasts. Medium was removed, cells were washed twice with $1 \times \mathrm{PBS}$ and incubated in serum-free DMEM for a further 48 hours.

\section{Fluorescence-activated cell sorting (FACS)}

Directly as well as indirectly co-cultured cells were lifted with $0.05 \%$ trypsin/5mM EDTA $(\mathrm{pH} 8)$, washed with complete medium and prepared for FACS in DMEM containing 2\% FCS. CCD-1068SK fibroblasts were sorted based on green fluorescence using the BD FACS VANTAGE, collected in DMEM containing 2\% FCS and used for further RNA and protein analysis.

\section{Oligo GEArray ${ }^{\circledast}$ human extracellular and adhesion molecules microarray analysis}

RNA was extracted from CCD-1068SK fibroblast using the RNeasy ${ }^{\circ}$ MinElute ${ }^{\mathrm{Tm}}$ Cleanup Kit (Qiagen), according to the manufacturer's instructions. The TrueLabelingAMP $^{\text {mi }} 2.0$ kit (SABiosciences) was used to synthesize cDNA from $3 \mu \mathrm{g}$ of each RNA sample. The amplified cDNA then formed the template for further cRNA synthesis, also using the TrueLabeling-AMP ${ }^{\mathrm{m}} 2.0$ kit. The cRNA was purified using the ArrayGrade ${ }^{\text {tw }}$ cRNA Cleanup Kit (SABiosciences) and hybridized against Oligo GEArrays ${ }^{\circ}$ nylon membranes overnight at $60^{\circ} \mathrm{C}$ with continuous rotation. Binding of biotinylated cRNA probes was detected using alkaline phosphatase-conjugated streptavidin together with the Chemiluminescent Detection Kit (SABiosciences). Array images were visualized using the Syngene G:Box Chemi system. The images were uploaded onto the web-based GEArray Expression Analysis Suite for further analysis. The microarrays were done in duplicate, background was normalized against two empty spots on each array and gene expression was normalized against ribosomal protein S27a (RPS27A) and $\beta$-actin (ACTB) gene expression.

\section{Quantitative real-time PCR}

Total RNA was isolated from CCD-1068SK fibroblasts using Qiazol reagent (Qiagen) according to the manufacturer's 
protocol and reverse transcribed using the ImProm- $\mathrm{II}^{\mathrm{Tm}} \mathrm{Re}-$ verse Transcription System (Promega). cDNA generated from $1 \mu \mathrm{g}$ of total RNA was used for quantitative PCR with the KAPA SYBR ${ }^{\circ}$ FAST qPCR Kit (KAPA Biosystems) and the relevant primer sets (Table 2) on a LightCycler ${ }^{\ominus} 480 \mathrm{II}$ System (Roche). To determine relative gene expression, results were analysed using the $2^{-\Delta \Delta C} \mathrm{~T}$ method [45] and normalised to GAPDH expression.

\section{Western blot analysis}

Cells were lysed in $1 \times$ RIPA buffer (Invitrogen) containing $1 \times$ protease inhibitor (Roche) and $1 \times$ phosphatase inhibitor (Roche), and quantitated using the $\mathrm{BCA}^{\mathrm{m}}$ Protein assay kit (Pierce). Approximately 20 to 30 $\mu \mathrm{g}$ of protein was heat-denatured at $95^{\circ} \mathrm{C}$, separated via SDS-polyacrylamide gel electrophoresis and transferred to a nitrocellulose membrane. Membranes were blocked in 5\% milk in TBS-Tween (TBST) for 1 hour and probed with the following primary antibodies at $4^{\circ} \mathrm{C}$ overnight: CTGF/CCN2 (L-20) (Santa Cruz Biotechnology), Smad7 (G-23) (Santa Cruz Biotechnology), type I collagen (Southern Biotech), pERK1,2 (T202/Y204) (Cell Signalling), Erk2 (Santa Cruz Biotechnology), and $\beta$-tubulin (Santa Cruz Biotechnology). After washing with TBST, membranes were incubated with the appropriate secondary antibody for 1 hour at room temperature. Protein levels were visualized by chemiluminscence using the LumiGlo $^{\circ}$ Reserve Substrate (KPL) and the VisionWorks LS Biospectrum $^{\mathrm{TM}} 500$ Imaging System (UVP).

\section{Transient transfections}

CCD-1068SK fibroblasts were plated at a density of $2 \times 10^{5}$ cells per well in 6-well plates and allowed to settle overnight to reach a final confluence of ca. 50\%. For geneknockdown experiments, Transfectin lipid reagent (BioRad) was added in a 2:1 ratio to $20-80 \mu \mathrm{M}$ CCN2 siRNA or $80 \mu \mathrm{M}$ Smad7 siRNA (Dharmacon), respectively, in serum-free DMEM and incubated at room temperature for $20 \mathrm{~min}$ before being added drop-wise to the cells. Cells were incubated overnight, medium was changed to serum-free DMEM and cells were incubated for a further 24 hours before continuing with RNA and protein extractions as described above. CCD-1068SK fibroblasts transfected with an equal amount of scrambled control siRNA-A (Santa Cruz Biotechnology) were used as a negative control.

To transiently overexpress Smad7, $1 \mu \mathrm{g}$ of the plasmid pORF9-hSmad7 (InvivoGen) in $150 \mathrm{mM} \mathrm{NaCl}$ was added to $2 \mu \mathrm{l} \mathrm{JetPEI}^{\odot}$ reagent (Polyplus) in $150 \mathrm{mM} \mathrm{NaCl}$ and incubated at room temperature for $20 \mathrm{~min}$. A total volume of $200 \mu \mathrm{l}$ transfection mixture was then added drop-wise to the cells. $8 \mathrm{~h}$ and $48 \mathrm{~h}$ post transfection, RNA and protein were extracted from the cells and used for further analysis as described above.

\section{Analysing the incorporation of $\left[{ }^{3} \mathrm{H}\right]$-proline into secreted a1(I) and a2(I) procollagen}

CCD-1068SK fibroblasts at a density of $2 \times 10^{5}$ cells were mixed with an equal number of MCF12A or MDA-MB231 cells, seeded into 6-well plates and allowed to settle overnight. Cells were then washed twice with $1 \times \mathrm{PBS}$, after which $2 \mathrm{ml}$ serum-free DMEM with $20 \mu \mathrm{Ci} / \mathrm{ml}$ $\left[{ }^{3} \mathrm{H}\right]$-proline (American Radiolabeled Chemicals Inc), 50 $\mathrm{mg} / \mathrm{ml}$ ascorbic acid and $50 \mathrm{mg} / \mathrm{ml} \beta$-aminopropionitrile was added to each well and incubated for 20 hours.

Medium was removed from cells, transferred to $2 \mathrm{ml}$ microfuge tube and acetic acid was added to a final concentration of $0.5 \mathrm{M}$. Medium proteins were digested with $100 \mu \mathrm{g} / \mathrm{ml}$ pepsin for $4 \mathrm{~h}$ at $20^{\circ} \mathrm{C}$, with rotation. Digested medium was transferred to dialysis tubing and dialyzed overnight against $50 \mathrm{mM}$ Tris, pH 7.5, with one buffer change after 2 hours. Medium was transferred back into microfuge tubes and precipitated with TCA overnight at $4^{\circ} \mathrm{C}$. The samples were centrifuged at $11000 \mathrm{rpm}$ for

Table 2 Primers used for quantitative real-time PCR

\begin{tabular}{|c|c|c|c|c|}
\hline Gene name & Primers & Annealing temp. & Product size & Ref. \\
\hline \multirow[t]{2}{*}{ GAPDH } & F: GGCTCTCCAGAACATCATCC & $60^{\circ} \mathrm{C}$ & $192 \mathrm{bp}$ & This study \\
\hline & R: GCCTGCTTCACCACCTTC & & & \\
\hline \multirow[t]{2}{*}{ COL1A1 } & F: CAGCCGCTTCACCTACAGC & $60^{\circ} \mathrm{C}$ & $83 \mathrm{bp}$ & [46] \\
\hline & R: TITTGTATTCAATCAGTGTCTTGCC & & & \\
\hline \multirow[t]{2}{*}{ COL1A2 } & F: GATTGAGACCCTTCTTACTCCTGAA & $60^{\circ} \mathrm{C}$ & $78 \mathrm{bp}$ & {$[47]$} \\
\hline & R: GGGTGGCTGAGTCTCAAGTCA & & & \\
\hline \multirow[t]{2}{*}{ CCN2 } & F: GTTTGGCCCAGACCCAACT & $60^{\circ} \mathrm{C}$ & $650 \mathrm{bp}$ & This study \\
\hline & R: GTGCAGCCAGAAAGCTCAAA & & & \\
\hline \multirow[t]{2}{*}{ MMP1 } & F: ATCCACTCCCCATTTCACAA & $60^{\circ} \mathrm{C}$ & $867 \mathrm{bp}$ & This study \\
\hline & R: TCCTGCAGTTGAACCAGCTA & & & \\
\hline \multirow[t]{2}{*}{ Smad7 } & F: CCAGATAATTCGTTCCCCCTGT & $60^{\circ} \mathrm{C}$ & $137 \mathrm{bp}$ & [48] \\
\hline & R: CCTTAGCCGACTCTGCGAACTA & & & \\
\hline
\end{tabular}


$15 \mathrm{~min}$, washed twice with acetone, air-dried and dissolved in $40 \mu \mathrm{l}$ of SDS-Page loading buffer. An equal volume of each sample was heat-denatured at $95^{\circ} \mathrm{C}$ for 5 minutes and run on an $8 \%$ SDS-PAGE gel (with $4 \%$ stacking gel) for 80 minutes at $180 \mathrm{~V}$. The gel was soaked in $1 \mathrm{M}$ sodium salicylate for 1 hour, washed in distilled water for another hour and placed on $3 \mathrm{~mm}$ Whatman paper, covered with saran wrap and vacuum dried at $70^{\circ} \mathrm{C}$ for 2 hours. The dried gel was placed in a cassette and exposed to film for 7 days at $-80^{\circ} \mathrm{C}$, after which it was developed and fixed.

\section{Statistical analysis}

All experiments were performed in triplicate and repeated at least twice. Standard deviations (SD) were calculated from triplicate samples by means of the twotailed Student's t-test and a p-value $\leq 0.05$ was regarded as statistically significant.

\section{Ethical approval}

No animal or human work has been performed in this study; therefore no ethics committee approval was required.

\section{Additional file}

Additional file 1: Table S1. Genes included on the Extracellular Matrix and Adhesion Molecules OligoGEArray.

\section{Abbreviations}

ECM: Extracellular matrix; CTGF: Connective tissue growth factor;

TGF $\beta$ : Transforming growth factor beta.

\section{Competing interests}

The authors declare that they have no competing interests.

\section{Authors' contributions}

BAR and GS participated in the design of the study, carried out the molecular and biochemical experiments and drafted the manuscript. MIP conceived the study. VDL and MIP participated in the design of the study and coordination and helped to draft the manuscript. All authors read and approved the final manuscript.

\section{Acknowledgements}

This work is based upon research supported by the International Centre for Genetic Engineering and Biotechnology (ICGEB), South African Research Chairs Initiative of the Department of Science and Technology and the National Research Foundation, the South African Medical Research Council and the University of Cape Town. GS was funded by grants from the PRF and the MRC.

\section{Author details}

${ }^{1}$ International Centre for Genetic Engineering and Biotechnology (ICGEB), Anzio Rd Observatory, Cape Town 7925, South Africa. ${ }^{2}$ Division of Medical Biochemistry \& the Institute of Infectious Diseases and Molecular Medicine, Faculty of Health Sciences, University of Cape Town, Cape Town, South Africa. ${ }^{3}$ Present address: Division of Haematology, Faculty of Medicine and Health Sciences, University of Stellenbosch, Franzie van Zyl Drive, Tygerberg 7505, South Africa.

Received: 7 August 2013 Accepted: 25 September 2013 Published: 3 October 2013

\section{References}

1. Kalluri R, Zeisberg M: Fibroblasts in cancer. Nat Rev Cancer 2006, 6:392-401.
2. Weigelt B, Bissell MJ: Unraveling the microenvironmental influences on the normal mammary gland and breast cancer. Semin Cancer Biol 2008, 18:311-321.

3. Beacham DA, Cukierman E: Stromagenesis: the changing face of fibroblastic microenvironments during tumor progression. Semin Cancer Biol 2005, 15:329-341.

4. Hanahan D, Weinberg RA: Hallmarks of cancer: the next generation. Cell 2011, 144:646-674.

5. Parmar H, Cunha GR: Epithelial-stromal interactions in the mouse and human mammary gland in vivo. Endocr Relat Cancer 2004, 11:437-458.

6. Bissell MJ, Radisky DC, Rizki A, Weaver VM, Petersen OW: The organizing principle: microenvironmental influences in the normal and malignant breast. Differentiation Res Biol Diver 2002, 70:537-546.

7. Gaggioli C: Collective invasion of carcinoma cells: when the fibroblasts take the lead. Cell Adh Migr 2008, 2:45-47.

8. Hu M, Polyak K: Molecular characterisation of the tumour microenvironment in breast cancer. Eur J Cancer 2008, 44:2760-2765.

9. Shekhar MP, Pauley R, Heppner G: Host microenvironment in breast cancer development: extracellular matrix-stromal cell contribution to neoplastic phenotype of epithelial cells in the breast. BCR 2003, 5:130-135.

10. Tlsty TD, Hein PW: Know thy neighbor: stromal cells can contribute oncogenic signals. Curr Opin Genet Dev 2001, 11:54-59.

11. Bornstein P: Matricellular proteins: an overview. J Cell Communication Signal 2009, 3:163-165.

12. Chen CC, Lau LF: Functions and mechanisms of action of CCN matricellular proteins. Int J Biochem Cell Biol 2009, 41:771-783.

13. Grotendorst GR, Okochi H, Hayashi N: A novel transforming growth factor beta response element controls the expression of the connective tissue growth factor gene. Cell Growth Differentiation Mole Biol J Am Assoc Cancer Res 1996, 7:469-480.

14. Leask A, Holmes A, Black CM, Abraham DJ: Connective tissue growth factor gene regulation. Requirements for its induction by transforming growth factor-beta 2 in fibroblasts. J Bio/ Chem 2003, 278:13008-13015.

15. Hishikawa K, Nakaki T, Fujii T: Transforming growth factor-beta(1) induces apoptosis via connective tissue growth factor in human aortic smooth muscle cells. Eur J Pharmacol 1999, 385:287-290.

16. Holmes A, Abraham DJ, Sa S, Shiwen X, Black CM, Leask A: CTGF and SMADs, maintenance of scleroderma phenotype is independent of SMAD signaling. J Biol Chem 2001, 276:10594-10601.

17. Blom IE, Goldschmeding R, Leask A: Gene regulation of connective tissue growth factor: new targets for antifibrotic therapy? Matrix Biol J Int Soc Matrix Biol 2002, 21:473-482

18. Shi-wen X, Stanton LA, Kennedy L, Pala D, Chen Y, Howat SL, Renzoni EA Carter DE, Bou-Gharios G, Stratton RJ, et al: CCN2 is necessary for adhesive responses to transforming growth factor-beta1 in embryonic fibroblasts. J Biol Chem 2006, 281:10715-10726.

19. Quan T, Shao Y, He T, Voorhees JJ, Fisher GJ: Reduced expression of connective tissue growth factor (CTGF/CCN2) mediates collagen loss in chronologically aged human skin. J Invest Dermatol 2010, 130:415-424.

20. Ramirez F, Tanaka S, Bou-Gharios G: Transcriptional regulation of the human alpha2(I) collagen gene (COL1A2), an informative model system to study fibrotic diseases. Matrix Biol J Int Soc Matrix Biol 2006, 25:365-372.

21. Ghosh AK: Factors involved in the regulation of type I collagen gene expression: implication in fibrosis. Exp Biol Med 2002, 227:301-314

22. Dzobo K, Leaner VD, Parker MI: Feedback regulation of the alpha2(1) collagen gene via the Mek-Erk signaling pathway. IUBMB life 2012, 64:87-98.

23. Bierie B, Moses HL: TGF-beta and cancer. Cytokine Growth Factor Rev 2006, 17:29-40.

24. Orimo A, Gupta PB, Sgroi DC, Arenzana-Seisdedos F, Delaunay T, Naeem R, Carey VJ, Richardson AL, Weinberg RA: Stromal fibroblasts present in invasive human breast carcinomas promote tumor growth and angiogenesis through elevated SDF-1/CXCL12 secretion. Cell 2005, 121:335-348.

25. Nakerakanti SS, Bujor AM, Trojanowska M: CCN2 is required for the TGF-beta induced activation of Smad1-Erk1/2 signaling network. PloS one 2011, 6:e21911.

26. Kopp J, Preis E, Said H, Hafemann B, Wickert L, Gressner AM, Pallua N, Dooley $S$ : Abrogation of transforming growth factor-beta signaling by SMAD7 inhibits collagen gel contraction of human dermal fibroblasts. J Biol Chem 2005, 280:21570-21576.

27. Hayashi H, Abdollah S, Qiu Y, Cai J, Xu YY, Grinnell BW, Richardson MA Topper JN, Gimbrone MA Jr, Wrana JL, Falb D: The MAD-related protein Smad7 associates with the TGFbeta receptor and functions as an antagonist of TGFbeta signaling. Cell 1997, 89:1165-1173. 
28. Nakao A, Afrakhte M, Moren A, Nakayama T, Christian JL, Heuchel R, Itoh S, Kawabata M, Heldin NE, Heldin CH, ten Dijke P: Identification of Smad7, a TGFbeta-inducible antagonist of TGF-beta signalling. Nature 1997, 389:631-635.

29. von Gersdorff G, Susztak K, Rezvani F, Bitzer M, Liang D, Bottinger EP: Smad3 and Smad4 mediate transcriptional activation of the human Smad7 promoter by transforming growth factor beta. J Biol Chem 2000, 275:11320-11326.

30. Bhowmick NA, Chytil A, Plieth D, Gorska AE, Dumont N, Shappell S, Washington MK, Neilson EG, Moses HL: TGF-beta signaling in fibroblasts modulates the oncogenic potential of adjacent epithelia. Science 2004, 303:848-851.

31. Kunz-Schughart LA, Knuechel R: Tumor-associated fibroblasts (part II): Functional impact on tumor tissue. Histol Histopathol 2002, 17:623-637.

32. Massague J: TGFbeta in Cancer. Cell 2008, 134:215-230.

33. Mantovani A, Allavena P, Sica A, Balkwill F: Cancer-related inflammation. Nature 2008, 454:436-444.

34. Ulloa L, Doody J, Massague J: Inhibition of transforming growth factorbeta/SMAD signalling by the interferon-gamma/STAT pathway. Nature 1999, 397:710-713.

35. Bauge C, Legendre F, Leclerca S, Elissalde JM, Pujol JP, Galera P, Boumediene K: Interleukin-1 beta impairment of transforming growth factor beta1 signaling by down-regulation of transforming growth factor beta receptor type II and up-regulation of Smad7 in human articular chondrocytes. Arthritis Rheum 2007, 56:3020-3032.

36. Chen Y, Blom IE, Sa S, Goldschmeding R, Abraham DJ, Leask A: CTGF expression in mesangial cells: involvement of SMADs, MAP kinase, and PKC. Kidney Int 2002, 62:1149-1159.

37. Stratton R, Rajkumar V Ponticos M, Nichols B, Shiwen X, Black CM, Abraham DJ, Leask A: Prostacyclin derivatives prevent the fibrotic response to TGFbeta by inhibiting the Ras/MEK/ERK pathway. FASEB J Off Pub Fed Am Soc Exp Biol 2002, 16:1949-1951.

38. Sato M, Shegogue D, Hatamochi A, Yamazaki S, Trojanowska M: Lysophosphatidic acid inhibits TGF-beta-mediated stimulation of type I collagen mRNA stability via an ERK-dependent pathway in dermal fibroblasts. Matrix Biol J Int Soc Matrix Biol 2004, 23:353-361.

39. Bhogal RK, Bona CA: Regulatory effect of extracellular signal-regulated kinases (ERK) on type I collagen synthesis in human dermal fibroblasts stimulated by IL-4 and IL-13. Int Rev Immunol 2008, 27:472-496.

40. Pannu J, Nakerakanti S, Smith E, ten Dijke P, Trojanowska M: Transforming growth factor-beta receptor type I-dependent fibrogenic gene program is mediated via activation of Smad1 and ERK1/2 pathways. J Biol Chem 2007, 282:10405-10413.

41. Chen CC, Chen N, Lau LF: The angiogenic factors Cyr61 and connective tissue growth factor induce adhesive signaling in primary human skin fibroblasts. J Biol Chem 2001, 276:10443-10452.

42. Fenhalls G, Geyp M, Dent DM, Parker MI: Breast tumour cell-induced downregulation of type I collagen mRNA in fibroblasts. Br J Cancer 1999, 81:1142-1149.

43. van Kempen LC, van Muijen GN, Ruiter DJ: Stromal responses in human primary melanoma of the skin. Front Biosci J Virt Librany 2005, 10:2922-2931.

44. Saad S, Bendall $\sqcup$, James A, Gottlieb DJ, Bradstock KF: Induction of matrix metalloproteinases MMP-1 and MMP-2 by co-culture of breast cancer cells and bone marrow fibroblasts. Breast Cancer Res Treat 2000, 63:105-115.

45. Livak KJ, Schmittgen TD: Analysis of relative gene expression data using real-time quantitative PCR and the 2(-Delta Delta $C(T))$ Method. Methods 2001, 25:402-408.

46. Martin I, Jakob M, Schafer D, Dick W, Spagnoli G, Heberer M: Quantitative analysis of gene expression in human articular cartilage from normal and osteoarthritic joints. Osteoarthritis and cartilage / OARS, Osteoarthritis Res Soc 2001, 9:112-118.

47. Sengupta PK, Smith EM, Kim K, Murnane MJ, Smith BD: DNA hypermethylation near the transcription start site of collagen alpha2(I) gene occurs in both cancer cell lines and primary colorectal cancers. Cancer Res 2003, 63:1789-1797.

48. Koinuma D, Shinozaki M, Komuro A, Goto K, Saitoh M, Hanyu A, Ebina M, Nukiwa T, Miyazawa K, Imamura T, Miyazono K: Arkadia amplifies TGF-beta superfamily signalling through degradation of Smad7. EMBO J 2003, 22:6458-6470.

doi:10.1186/1478-811X-11-75

Cite this article as: van Rooyen et al:: Tumour cells down-regulate CCN2 gene expression in co-cultured fibroblasts in a Smad7- and ERK-dependent manner. Cell Communication and Signaling 2013 11:75.

\section{Submit your next manuscript to BioMed Central and take full advantage of:}

- Convenient online submission

- Thorough peer review

- No space constraints or color figure charges

- Immediate publication on acceptance

- Inclusion in PubMed, CAS, Scopus and Google Scholar

- Research which is freely available for redistribution 